\title{
Differences in Response to Pulmonary Rehabilitation in Idiopathic Pulmonary Fibrosis and Chronic Obstructive Pulmonary Disease
}

\author{
Ryo Kozu $^{a}$ Hideaki Senjyu $^{b}$ Sue C. Jenkins ${ }^{e}$ Hiroshi Mukae $^{c, d}$ \\ Noriho Sakamoto $^{d}$ Shigeru Kohno $^{d}$ \\ ${ }^{a}$ Department of Rehabilitation Medicine, Nagasaki University Hospital, ${ }^{b}$ Courses of Health Sciences, \\ Nagasaki University Graduate School of Biomedical Sciences, Nagasaki, 'Division of Respiratory Disease, \\ University of Occupational and Environmental Health, Kitakyushu, and d Second Department of Internal Medicine,

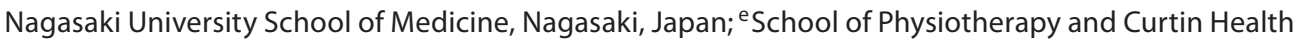 \\ Innovation Research Institute, Curtin University of Technology, Perth, W.A., Australia
}

\section{Key Words \\ Idiopathic pulmonary fibrosis - Chronic obstructive pulmonary disease $\cdot$ Pulmonary rehabilitation • \\ Exercise training}

\begin{abstract}
Background: The benefits of pulmonary rehabilitation in chronic obstructive pulmonary disease (COPD) are well recognized. However, whether individuals with idiopathic pulmonary fibrosis (IPF) benefit is less clear. Objectives: To evaluate the effects of pulmonary rehabilitation in subjects with IPF and compare their responses with a group of COPD subjects who underwent an identical program. Methods: Forty-five subjects with IPF and 45 age- and Medical Research Council grade-matched COPD subjects were recruited. Subjects completed an 8-week outpatient pulmonary rehabilitation program. Dyspnea, peripheral muscle force, exercise capacity (6-min walk distance, 6MWD), activities of daily living, and health status (36-item short-form survey, SF-36) were assessed at baseline, immediately following and at 6 months following completion of the program. Results: Adherence to the program was similar in both groups. Significant improvements in dyspnea, muscle force, exercise capacity and ADL
\end{abstract}

were observed in both groups (all $p<0.05$ ); however, the magnitude of improvement in all outcomes was less in the IPF group [mean (95\% Cl) improvement in 6MWD, IPF 16.2 (7.1-25.4); COPD 53.1 (44.9-61.2)]. All domains of SF-36, with the exception of social function, improved (all $p<0.05$ ) in the COPD group; however, there were no changes in SF-36 scores in the IPF group. The benefits were well maintained in the COPD group at 6 months, but, with the exception of the ADL score, the benefits were no longer present in the IPF group. Conclusions: Pulmonary rehabilitation in IPF produces only modest short-term gains in dyspnea, exercise capacity and $A D L$, but does not improve health status.

Copyright $\odot 2010$ S. Karger AG, Basel

\section{Introduction}

Idiopathic pulmonary fibrosis (IPF), a chronic progressive disorder with a poor prognosis, is the most common and clinically important interstitial lung disease (ILD) [1]. Progressive dyspnea, frequently accompanied by a nonproductive cough; is the hallmark symptom and causes exercise limitation. Exertional dyspnea and exercise limitation lead to difficulties in performing daily ac-

\section{KARGER}

Fax +4161306 1234

E-Mail karger@karger.ch

www.karger.com (c) 2010 S. Karger AG, Basel

0025-7931/11/0813-0196\$38.00/0

Accessible online at:

www.karger.com/res
Ryo Kozu, PT, PhD

Department of Rehabilitation Medicine

Nagasaki University Hospital

1-7-1 Sakamoto, Nagasaki 852-8501 (Japan)

Tel. +8195819 7258, Fax +8195819 7259, E-Mail ryokozu@ nagasaki-u.ac.jp 
tivities and are major contributors to the impairments in health-related quality of life (HRQoL) [2]. Treatment options are limited and conventional pharmacotherapy for IPF has not been shown convincingly to improve morbidity, physiological or radiological markers of disease severity, HRQoL or survival [1].

The presence of exercise limitation and significant disability suggests that individuals with IPF are likely to be appropriate candidates for pulmonary rehabilitation [3]. Although the benefits of rehabilitation have been extensively reported in subjects with chronic obstructive pulmonary disease (COPD) [4], data to support rehabilitation in subjects with IPF are scant. Studies on subjects without COPD that have included IPF subjects report improvements in dyspnea, exercise capacity and HRQoL following rehabilitation [5-9]. Recently, a study of a large cohort $(n=113)$ of patients with ILD reported similar findings [10]. One randomized controlled trial on subjects with IPF demonstrated benefits from pulmonary rehabilitation; however, the subjects had relatively mild disease [11]. To date, the effects of pulmonary rehabilitation in subjects with IPF and associated moderate to severe disability are unknown.

The guidelines for exercise training in subjects with chronic lung disease are largely based on studies in COPD cohorts [12], with the assumption that the recommendations are applicable to subjects with other lung diseases. The pathophysiology and exercise limitation in IPF differs from COPD [13]. In COPD, ventilatory limitation and skeletal muscle dysfunction are the predominant factors contributing to exercise limitation [14], whereas impaired pulmonary gas exchange $[15,16]$ and circulatory factors [17] may be the primary limitations to exercise in IPF. Exercise programs, especially high-intensity endurance training, improve muscle function, and decrease lactic acidosis at a given level of submaximal exercise, resulting in decreased ventilatory demand and dyspnea in COPD [18]. It is unclear whether this mechanism similarly contributes to the benefits following exercise training in individuals with IPF. We hypothesized that a pulmonary rehabilitation program based on the guidelines developed for COPD would produce benefits of a smaller magnitude in IPF subjects than in a cohort with COPD.

The aims of the present study were to: (1) evaluate the effects of pulmonary rehabilitation on dyspnea, exercise capacity and health status in subjects with IPF who have functional limitations, and (2) compare the responses in subjects with IPF with the changes seen in a control group of COPD subjects who underwent an identical pulmonary rehabilitation program.

\section{Material and Methods}

\section{Study Design}

We performed a prospective nonrandomized open trial in which two subject cohorts (IPF and COPD) underwent an 8-week out-patient pulmonary rehabilitation program. Measures were made at baseline, immediately following the 8 -week program and at 6 months following completion of the program.

\section{Subjects}

Subjects were eligible to participate if they reported dyspnea on exertion leading to a limitation in daily activities [Medical Research Council (MRC) grade $>1$ ] [19] and were on stable medical treatment. The diagnosis of IPF was based on published criteria [1]. Individuals with collagen vascular disease, occupational lung disease, sarcoidosis, hypersensitivity pneumonitis and other idiopathic interstitial pneumonias were excluded. Other exclusions were MRC grade 5, severe orthopedic or neurological disorders limiting exercise performance, unstable cardiac disease, inability to understand or complete questionnaires and previous participation in a pulmonary rehabilitation program.

The control group comprised age- and MRC grade-matched COPD subjects. Since the pathophysiology and exercise limitation in IPF significantly differs from that seen in COPD, we matched subjects based on their functional limitation level due to dyspnea. The diagnosis of COPD was made according to published guidelines [20]. Exclusion criteria were identical to those for the IPF group.

Prior to recruitment, subjects in both groups were required to be clinically stable for at least 4 weeks. All patients were under the care of a respiratory physician. Medical treatment, including dose of oral corticosteroids and immunosuppressive drugs, was not changed during the rehabilitation program.

This study was approved by the Human Ethics Review Committee of Nagasaki University Graduate School of Biomedical Sciences and subjects gave written informed consent prior to participation.

\section{Baseline Assessments}

Baseline measurements comprised age, gender, body mass index, time since diagnosis, use of long-term oxygen therapy (LTOT) and oral corticosteroids, symptoms of cough, transthoracic echocardiographic data (right ventricular systolic pressure) and pulmonary function. The outcome measures in this study were dyspnea and functional status, peripheral muscle force, functional exercise capacity, limitation in daily activities and health status. These measures were made at baseline and repeated immediately following the 8-week program and at 6 months thereafter.

Spirometry, static lung volumes and lung diffusion capacity for carbon monoxide were measured in accordance with a standard protocol [21, 22]. Arterial blood gas tensions were measured at rest, and with oxygen supplementation for subjects who were receiving LTOT.

Dyspnea and functional status were evaluated using the MRC dyspnea grade [19] and the baseline dyspnea index (BDI)/transition dyspnea index (TDI), respectively [23].

Quadriceps force (QF) was measured as the peak force (kilograms) developed during a maximal isometric knee extension maneuver with the hip and knee in $90^{\circ}$ flexion using a hand-held dynamometer with a fixing belt ( $\mu$ Tas F-1; Anima Corporation, 
Tokyo, Japan). The highest value from three attempts on the dominant side was recorded and expressed in kilograms and as a percentage of body weight. This protocol has good test-retest reliability with an intraclass correlation coefficient of 0.94 [24]. Handgrip force was assessed with a hydraulic hand dynamometer (Smedley's Dynamometer; TTM, Tokyo, Japan). Peak force (kilograms) was measured on the dominant hand and the highest value of three attempts was used in the analyses.

The 6-minute walk test (6MWT) was performed according to published guidelines along a 30-meter corridor [25]. The test was performed twice on consecutive days and the greatest distance [6-min walk distance (6MWD)] was used in the analysis. Oxygen saturation was monitored continuously throughout the test and the test was terminated if oxygen saturation fell to below $80 \%$. Pre-exercise and the lowest oxygen saturation recorded during the test were recorded. Heart rate was monitored continuously throughout the test (Polar, Polar Electro, Oy, Finland).

Subjects performed a symptom-limited incremental cycle ergometry test (ICET) on an electrically braked cycle ergometer (Rehcor version 2.21; Lode BV, Groningen, The Netherlands) to volitional exhaustion. After a period of rest followed by $2 \mathrm{~min}$ of unloaded pedaling, work load was increased by $5 \mathrm{~W} / \mathrm{min}$ for subjects with MRC grade 4 and $10 \mathrm{~W} / \mathrm{min}$ for those with grades 2 and 3. Test termination was determined by the subject or by the tester if oxygen saturation fell below $80 \%$. At the end of each minute, symptom scores for dyspnea [26] and leg fatigue [26] were recorded. Peak work rate (PWR) was recorded as the maximum work rate (watts) maintained for at least $30 \mathrm{~s}$. Dyspnea ratings obtained from this test were used as a target for subjects to regulate and monitor the intensity of exercise during the initial stages of the rehabilitation program. This test was only performed at the baseline assessment.

During the 6MWT and ICET, subjects receiving LTOT used the same flow rate of supplemental oxygen as prescribed for their normal daily activities. All follow-up exercise tests were performed with subjects using the same flow rate of supplemental oxygen as used during the baseline exercise tests.

Limitations in activities of daily living (ADL) were assessed using a standard scoring system [27]. This system evaluates six fundamental daily activities (feeding, transfer, dressing, bathing, shopping and transportation) and assigns a score of 1 (independent) or 0 (dependent) for each activity. The total score was used in the analysis.

Health status was measured using the self-administered Medical Outcomes Study 36-Item Short-Form Health Survey (SF-36, Version 2) adapted and psychometrically validated for the Japanese population [28].

\section{Pulmonary Rehabilitation Program}

Subjects attended an 8-week outpatient program comprising two classes each week (90 min duration) that included exercise training, breathing retraining, and education. The same training protocol was used for the IPF and COPD cohorts. During each class, subjects performed 40-50 min of exercise supervised by a physiotherapist. Subjects were also instructed to undertake daily exercise at home and were encouraged to continue their homebased program at the end of the 8 weeks. Adherence to the home program was assessed using a diary card.

Exercise training included stretches and endurance and strength training. Lower-limb endurance training was performed using a cycle ergometer with the initial workload prescribed at $50 \%$ of the PWR achieved on the baseline cycle ergometer test. In the early stages of the program, cycling was limited to 5-10 min and progressively increased, within symptom tolerance, to $20 \mathrm{~min}$ of continuous cycling. Once subjects had achieved 20 min cycling, the workload was increased. Upper-limb endurance training comprised repetitive bilateral shoulder flexion and abduction using a light weight and synchronized with expiration for $2 \mathrm{~min}$. Strength training was accomplished using free weights or the subject's own body weight. One set of 10 repetitions was initially prescribed increasing to 3 sets when the subject could perform the exercises without any difficulty. Arterial oxygen saturation was monitored during each session, and supplemental oxygen was given as necessary to maintain arterial oxygen saturation above $85 \%$. We recorded the duration of cycle-based exercise (minutes) and workload (watts) of all subjects for each of the exercise sessions.

Breathing retraining consisted of relaxation with breathing control, pursed-lip breathing and pacing during exercise training and ADL. The rationale for pursed-lip breathing in the IPF cohort was to assist subjects to control their breathing by reducing respiratory frequency. All subjects received the same instructions.

The education component was provided by a physiotherapist at each class and consisted of the benefits and importance of daily exercise, pacing and energy-conservation techniques to manage ADL and self-management strategies for coping with an exacerbation.

Subjects were considered to have completed the program if they attended at least $12(75 \%)$ of the 16 supervised sessions. At the end of the 8-week program, all subjects were encouraged to continue with their home exercise program; however, no formal maintenance program was provided.

\section{Statistical Analysis}

The Kolmogorov-Smirnov test was used to examine the distribution of the data. Data that did not conform to a normal distribution were transformed or analyzed using nonparametric tests. Differences between groups at baseline were assessed using unpaired $t$ tests, the Mann-Whitney $U$ test and the $\chi^{2}$ test. Withingroup and between-group changes following rehabilitation were evaluated using paired t tests, Wilcoxon signed-rank and MannWhitney U tests, respectively. Total work done (kilojoules) for each exercise session was compared using a two-way repeatedmeasures analysis of variance to account for group and time interaction. Pearson product-moment correlation or Spearman rank correlation were used to examine relationships between the changes in 6MWD and QF in both groups, and mean daily dose of corticosteroids and change in QF in subjects with IPF. Data are expressed as means \pm SD or $95 \%$ confidence intervals $(95 \% \mathrm{CI})$. All analyses were performed using SPSS software Version 16 (SPSS Inc., Chicago, Ill., USA).

\section{Results}

One hundred and twelve consecutive subjects were screened; of these, 90 were recruited to the study (fig. 1). Surgical lung biopsies were performed in 9 subjects with IPF. Baseline characteristics of the 90 subjects are shown 
Fig. 1. Participant flow diagram.

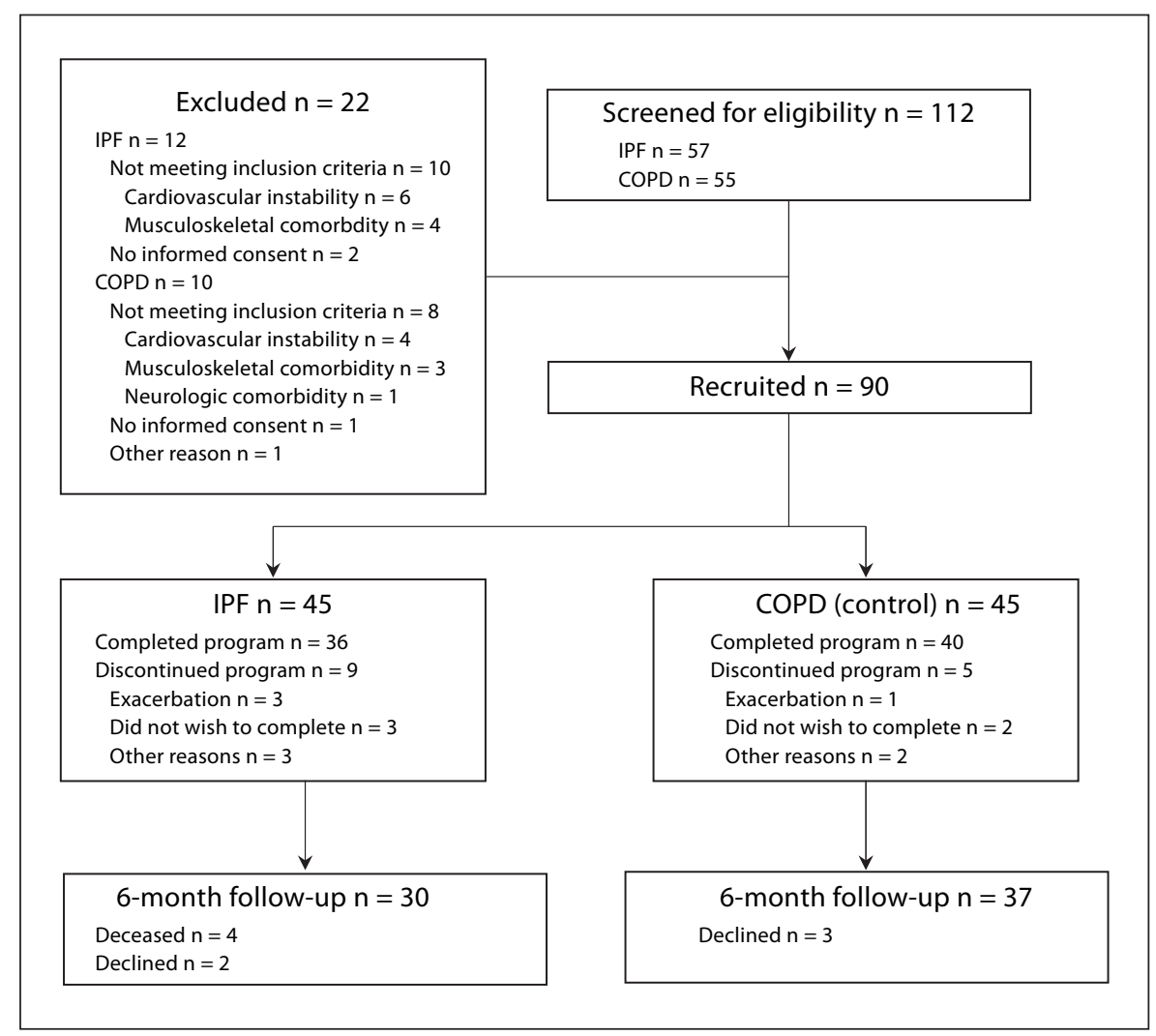

in table 1. A higher proportion of the IPF cohort reported cough as a major symptom (67 vs. $9 \%, \mathrm{p}<0.001$ ), and were prescribed LTOT (58 vs. $22 \%, \mathrm{p}<0.001$ ). The use of oral corticosteroids was higher $(\mathrm{p}=0.001)$ and $\mathrm{QF}$ (\% body weight) lower in the IPF group ( $\mathrm{p}=0.031$ ). $6 \mathrm{MWD}$ was similar in the two groups; however, the magnitude of desaturation during the 6MWT was greater in the IPF group (table 1). There were no significant differences between the groups in SF-36 scores (table 1).

\section{Adherence to the Rehabilitation Program}

Adherence to the program was similar in the two groups. The mean number of supervised sessions attended was $13.3 \pm 3.8$ and $14.1 \pm 2.7$ for the IPF and COPD groups, respectively $(\mathrm{p}=0.24)$. No adverse events were recorded during the program. Subjects completed an average of $3.9 \pm 1.9$ (IPF group) and $4.1 \pm 1.6$ (COPD group) sessions of home-based exercise each week ( $\mathrm{p}=$ 0.59 ).

Data for cycle ergometry training are displayed in figure 2 as total work done (kilojoules) and the intensity of training expressed as a percentage of the PWR achieved on the baseline ICET. There was a significant interaction between group and time for total work $(\mathrm{p}<0.001)$. The IPF subjects were unable to increase the intensity of exercise as rapidly as the COPD subjects due to dyspnea and/ or cough and profound desaturation. At the end of the program, training intensity was $33.6 \pm 22.1$ and $44.3 \pm$ $21.7 \mathrm{~W}(69 \pm 15 \%$ baseline PWR and $89 \pm 8 \%$ baseline PWR) in the IPF and COPD groups, respectively ( $\mathrm{p}=$ $0.037, p<0.001$ ). Total work performed was significantly lower in the IPF group compared to the COPD group (445 \pm 333 vs. $594 \pm 341 \mathrm{~kJ}, \mathrm{p}=0.013$ ).

\section{Effects of the Rehabilitation Program}

Seventy-six subjects (IPF $\mathrm{n}=36$, COPD $\mathrm{n}=40$ ) completed the 8 -week program. Attrition was $20 \%$ in the IPF group and $11 \%$ in the COPD group $(\mathrm{p}=0.24$, fig. 1$)$. Sixty-seven subjects (IPF $\mathrm{n}=30$, COPD $\mathrm{n}=37, \mathrm{p}=0.09$ ) completed the 6-month follow-up assessments. There were 4 deaths in the IPF group, all occurring during the follow-up period.

The 9 subjects with IPF who did not complete the program had lower ADL scores $(2.3 \pm 1.0, \mathrm{p}=0.004)$ and the physical functioning $(\mathrm{p}=0.047)$, vitality $(\mathrm{p}=0.002)$ and role emotional $(p=0.002)$ domains of the SF-36 com- 
Table 1. Baseline characteristics of the subjects

\begin{tabular}{|c|c|c|c|}
\hline Characteristics & $\begin{array}{l}\text { IPF group } \\
(\mathrm{n}=45)\end{array}$ & $\begin{array}{l}\text { COPD group } \\
(\mathrm{n}=45)\end{array}$ & $\begin{array}{l}\mathrm{p} \\
\text { value }\end{array}$ \\
\hline Age, years & $67.5 \pm 7.8$ & $67.3 \pm 5.1$ & 0.85 \\
\hline Gender, M/F & $37 / 8$ & $38 / 7$ & 0.78 \\
\hline BMI, kg/m² & $21.2 \pm 3.3$ & $20.8 \pm 2.2$ & 0.75 \\
\hline Time since diagnosis, years & $1.8 \pm 1.8$ & $1.7 \pm 1.7$ & 0.95 \\
\hline LTOT & $26(58 \%)$ & $10(22 \%)$ & 0.001 \\
\hline Oral corticosteroids & $20(44 \%)$ & $6(13 \%)$ & 0.001 \\
\hline Mean dose, mg/day & $22.6 \pm 7.8$ & $11.7 \pm 4.1$ & 0.001 \\
\hline Cough & $30(67 \%)$ & $4(9 \%)$ & 0.001 \\
\hline $\mathrm{RVSP}, \mathrm{mm} \mathrm{Hg}^{\mathrm{a}}$ & $47 \pm 21$ & $30 \pm 11$ & 0.001 \\
\hline \multicolumn{4}{|l|}{ Blood gas data } \\
\hline $\mathrm{PaO}_{2}$ at rest, $\mathrm{mm} \mathrm{Hg}^{\mathrm{b}}$ & $72.8 \pm 9.6$ & $73.3 \pm 8.0$ & 0.78 \\
\hline $\mathrm{PaCO}_{2}$ at rest, $\mathrm{mm} \mathrm{Hg}^{\mathrm{b}}$ & $40.8 \pm 5.0$ & $40.6 \pm 4.4$ & 0.89 \\
\hline $\mathrm{PaO}_{2}$ at rest, $\mathrm{mm} \mathrm{Hg}^{\mathrm{c}}$ & $69.3 \pm 8.8$ & $70.2 \pm 6.2$ & 0.76 \\
\hline $\mathrm{PaCO}_{2}$ at rest, $\mathrm{mm} \mathrm{Hg}$ & $42.1 \pm 4.8$ & $42.5 \pm 4.4$ & 0.81 \\
\hline \multicolumn{4}{|l|}{ Pulmonary function } \\
\hline $\mathrm{FEV}_{1}$, liters & $1.7 \pm 0.5$ & $1.1 \pm 0.5$ & 0.001 \\
\hline $\mathrm{FEV}_{1}, \%$ pred. & $80.1 \pm 17.3$ & $45.0 \pm 11.8$ & 0.001 \\
\hline FVC, liters & $2.0 \pm 0.6$ & $2.5 \pm 0.7$ & 0.001 \\
\hline FVC, \%pred. & $68.6 \pm 16$ & $81.3 \pm 23.4$ & 0.011 \\
\hline FRC, liters & $1.6 \pm 0.5$ & $4.2 \pm 1.0$ & 0.001 \\
\hline FRC, \%pred. & $65.4 \pm 17.8$ & $147 \pm 22.7$ & 0.001 \\
\hline TLC, liters & $3.0 \pm 0.8$ & $5.6 \pm 1.0$ & 0.001 \\
\hline TLC, \%pred. & $63.8 \pm 13.7$ & $109.9 \pm 14.5$ & 0.001 \\
\hline $\mathrm{DL}_{\mathrm{CO}}, \mathrm{ml} / \mathrm{min} / \mathrm{mm} \mathrm{Hg}$ & $6.0 \pm 2.5$ & $12.9 \pm 6.1$ & 0.001 \\
\hline $\mathrm{DL}_{\mathrm{CO}}, \%$ pred. & $38.8 \pm 20$ & $58.9 \pm 24.1$ & 0.001 \\
\hline \multicolumn{4}{|c|}{ Dyspnea and functional status } \\
\hline MRC grade & $3.0 \pm 0.8$ & $3.0 \pm 0.8$ & \\
\hline 2 & $14(31 \%)$ & $14(31 \%)$ & \\
\hline 3 & $15(33 \%)$ & $15(33 \%)$ & \\
\hline 4 & $16(36 \%)$ & $16(36 \%)$ & \\
\hline BDI focal score & $5.1 \pm 3$ & $5.2 \pm 2.7$ & 0.91 \\
\hline \multicolumn{4}{|l|}{ Muscle force } \\
\hline HF, kg & $23.2 \pm 9.1$ & $24.1 \pm 8.3$ & 0.62 \\
\hline QF, kg & $19.1 \pm 10.1$ & $22.1 \pm 9$ & 0.155 \\
\hline QF, \% body weight & $35.4 \pm 15.2$ & $42.3 \pm 14.5$ & 0.031 \\
\hline
\end{tabular}

\begin{tabular}{|c|c|c|c|}
\hline Characteristics & $\begin{array}{l}\text { IPF group } \\
(\mathrm{n}=45)\end{array}$ & $\begin{array}{l}\text { COPD group } \\
(\mathrm{n}=45)\end{array}$ & $\begin{array}{l}\mathrm{p} \\
\text { value }\end{array}$ \\
\hline \multicolumn{4}{|l|}{$\begin{array}{l}\text { Exercise capacity } \\
6 \mathrm{MWT}\end{array}$} \\
\hline 6MWD, m & $308 \pm 111$ & $318 \pm 109$ & 0.69 \\
\hline Pre-exercise $\mathrm{SpO}_{2}, \%$ & $95 \pm 2$ & $96 \pm 1$ & 0.001 \\
\hline Lowest $\mathrm{SpO}_{2}$ during test, $\%$ & $82 \pm 8$ & $91 \pm 5$ & 0.001 \\
\hline Desaturation, $\%$ & $13 \pm 8$ & $6 \pm 4$ & 0.001 \\
\hline Pre-exercise heart rate, bpm & $89 \pm 10$ & $85 \pm 10$ & 0.052 \\
\hline $\begin{array}{l}\text { Peak heart rate during test, } \\
\text { bpm }\end{array}$ & $121 \pm 14$ & $115 \pm 11$ & 0.04 \\
\hline Pre-exercise dyspnea & $0.2 \pm 0.5$ & $0.2 \pm 0.3$ & 0.95 \\
\hline Peak-exercise dyspnea & $4.9 \pm 1.3$ & $4.4 \pm 0.2$ & 0.03 \\
\hline \multicolumn{4}{|l|}{ ICET } \\
\hline PWR, W & $42.2 \pm 21.3$ & $48.8 \pm 23.3$ & 0.16 \\
\hline \multicolumn{4}{|l|}{$\mathrm{ADL}$} \\
\hline ADL score & $3.4 \pm 1.3$ & $3.5 \pm 1.4$ & 0.81 \\
\hline \multicolumn{4}{|l|}{ Health status } \\
\hline \multicolumn{4}{|l|}{ SF-36 } \\
\hline Physical functioning & $35.7 \pm 18.7$ & $38.8 \pm 22.4$ & 0.58 \\
\hline Role physical & $33.9 \pm 21.7$ & $32.2 \pm 21$ & 0.77 \\
\hline Bodily pain & $62.4 \pm 30.3$ & $61.2 \pm 29.3$ & 0.81 \\
\hline General health & $34.7 \pm 19.9$ & $33.3 \pm 17.5$ & 0.66 \\
\hline Vitality & $38.3 \pm 21.3$ & $37.1 \pm 18.5$ & 0.71 \\
\hline Social function & $48.3 \pm 23.7$ & $50.0 \pm 17.7$ & 0.75 \\
\hline Role emotional & $36.5 \pm 30.1$ & $38.5 \pm 26.9$ & 0.84 \\
\hline Mental health & $50.0 \pm 18.7$ & $49.9 \pm 18.2$ & 0.97 \\
\hline
\end{tabular}

Values are mean \pm SD or numbers and percentages of subjects. $\mathrm{BDI}=$ Baseline dyspnea index $\mathrm{BMI}=$ body mass index $; \mathrm{DL}_{\mathrm{CO}}=$ lung diffusion capacity for carbon monoxide; $\mathrm{FEV}_{1}=$ forced expiratory volume in $1 \mathrm{~s} ; \mathrm{FRC}=$ functional residual capacity; FVC = forced vital capacity; $\mathrm{HF}=$ handgrip force; $\mathrm{PaCO}_{2}=$ arterial carbon dioxide tension; $\mathrm{PaO}_{2}=$ arterial oxygen tension; \% pred. = percent predicted; $\mathrm{RVSP}=$ right ventricular systolic pressure; $\mathrm{SpO}_{2}=$ percutaneous oxygen saturation; TLC $=$ total lung capacity.

${ }^{a}$ RVSP data (IPF $n=40$, COPD $n=36$ ).

${ }^{b}$ Blood gas tensions shown for all 45 subjects in each group.

${ }^{\mathrm{c}}$ Blood gas tensions for the 19 subjects with IPF and 35 subjects with COPD who were not receiving LTOT.

pared to those who completed the program. In the COPD group, the 5 subjects who did not complete the program had a lower QF $(14.3 \pm 9.9 \mathrm{~kg}, \mathrm{p}=0.042)$.

Significant improvements in dyspnea, muscle force, $6 \mathrm{MWD}$ and ADL occurred in both groups following the program (table 2). These benefits were maintained at the 6-month follow-up in the COPD group. In contrast, with the exception of the ADL score, none of the improvements were maintained in the IPF group (table 2).

All subscales of the SF-36, with the exception of social function, improved (all $\mathrm{p}<0.05)$ in the COPD group fol-

lowing the program (table 2). In contrast, no significant changes were seen in the IPF group. At the 6-month follow-up, the improvement in physical functioning and mental health were maintained in the COPD group (table 2).

The magnitude of improvement in all outcomes was less in the IPF group than in the COPD group. At the 6-month follow-up, there was deterioration in the transition dyspnea index, 6MWD, and all subscales of the SF-36 in the IPF group when compared to baseline (table 3). 

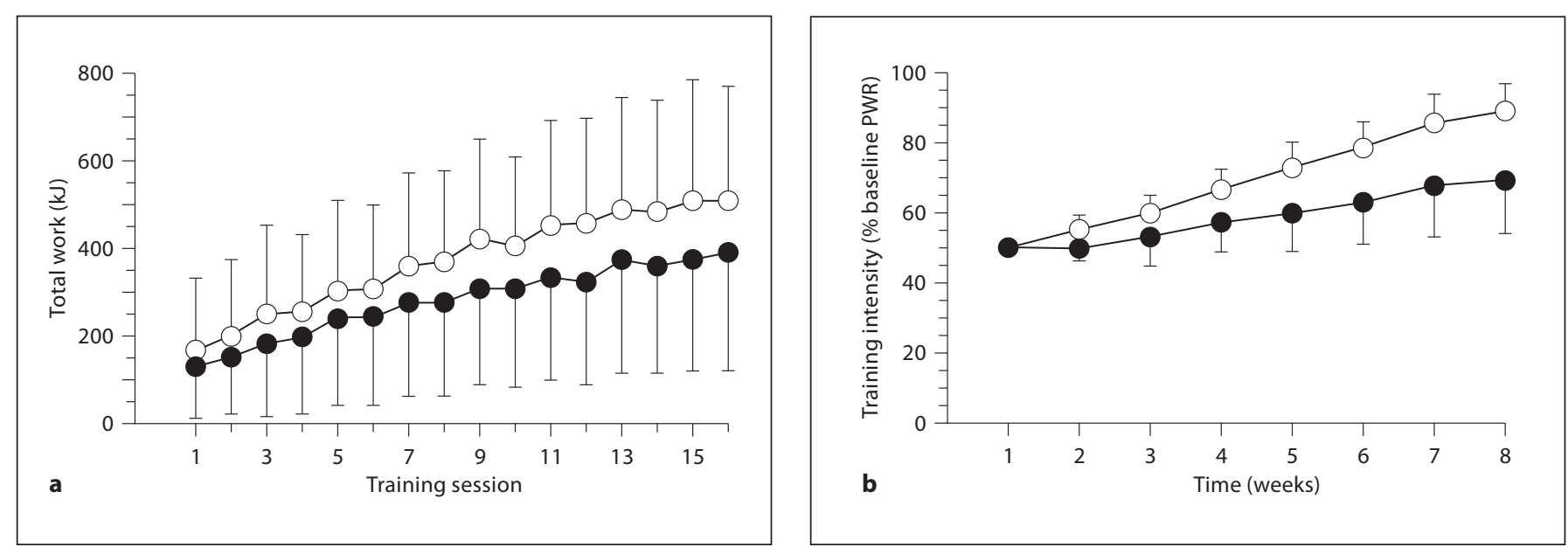

Fig. 2. Total work performed (kJ) during each training session (a) and training intensity (b) expressed as percent baseline PWR averaged for each week of training. Data are mean \pm SD for each group. $\bullet=$ IPF group; $\bigcirc=$ COPD group.

Table 2. Outcome measures of the subjects who completed program at baseline, and at 8 weeks and 6 months following pulmonary rehabilitation

\begin{tabular}{|c|c|c|c|c|c|c|}
\hline \multirow[t]{2}{*}{ Outcome measures } & \multicolumn{3}{|l|}{ IPF group } & \multicolumn{3}{|c|}{ COPD group } \\
\hline & $\begin{array}{l}\text { baseline } \\
(\mathrm{n}=36)\end{array}$ & $\begin{array}{l}8 \text { weeks } \\
(\mathrm{n}=36)\end{array}$ & $\begin{array}{l}6 \text { months } \\
(\mathrm{n}=30)\end{array}$ & $\begin{array}{l}\text { baseline } \\
(\mathrm{n}=40)\end{array}$ & $\begin{array}{l}8 \text { weeks } \\
(n=40)\end{array}$ & $\begin{array}{l}6 \text { months } \\
(\mathrm{n}=37)\end{array}$ \\
\hline \multicolumn{7}{|c|}{ Dyspnea and functional status } \\
\hline MRC grade & $3.0 \pm 0.8$ & $2.5 \pm 1.1^{* *}$ & $2.9 \pm 1$ & $3.0 \pm 0.8$ & $2.3 \pm 0.9^{* *}$ & $2.4 \pm 0.9^{* *}$ \\
\hline TDI focal score & & $0.8 \pm 1.7$ & $-0.9 \pm 0.9$ & & $1.8 \pm 1.7$ & $0.9 \pm 1.4$ \\
\hline \multicolumn{7}{|l|}{ Muscle force } \\
\hline $\mathrm{HF}, \mathrm{kg}$ & $24 \pm 9.2$ & $24.8 \pm 9.7^{*}$ & $24.4 \pm 9.7$ & $24.7 \pm 8.1$ & $26.1 \pm 8.4^{* *}$ & $25.3 \pm 8^{* *}$ \\
\hline $\mathrm{QF}, \mathrm{kg}$ & $20.4 \pm 10.5$ & $22.4 \pm 11.6^{* *}$ & $20.9 \pm 11.7$ & $23.0 \pm 8.6$ & $28.4 \pm 10.3^{* *}$ & $27.0 \pm 10.5^{* *}$ \\
\hline QF, \% body weightt & $36.8 \pm 15.8$ & $41.1 \pm 18.9^{* *}$ & $36.9 \pm 18.1$ & $43.8 \pm 13.4$ & $54 \pm 15.7^{* *}$ & $51.8 \pm 16.2^{* *}$ \\
\hline \multicolumn{7}{|l|}{ Exercise capacity } \\
\hline 6MWD, m & $323 \pm 109$ & $340 \pm 122^{* *}$ & $320 \pm 106$ & $325 \pm 107$ & $378 \pm 99^{* *}$ & $367 \pm 95^{* *}$ \\
\hline \multicolumn{7}{|l|}{$\mathrm{ADL}$} \\
\hline ADL score & $3.7 \pm 1.2$ & $4.8 \pm 1.1^{* *}$ & $4.3 \pm 1.2^{* *}$ & $3.6 \pm 1.3$ & $5.1 \pm 0.9^{* *}$ & $5.1 \pm 0.9^{* *}$ \\
\hline \multicolumn{7}{|l|}{ SF-36 Scale } \\
\hline Physical functioning & $38.6 \pm 19$ & $40.6 \pm 22.6$ & $37.8 \pm 23$ & $40.1 \pm 21.4$ & $47.1 \pm 19.5^{*}$ & $45.1 \pm 20^{*}$ \\
\hline Role physical & $34.9 \pm 21.5$ & $35.9 \pm 20.7$ & $30.4 \pm 23.7$ & $32.8 \pm 20.9$ & $42.7 \pm 22.7^{* *}$ & $39.7 \pm 22.8$ \\
\hline Bodily pain & $66.1 \pm 30$ & $63.4 \pm 28.1$ & $62.5 \pm 30.3^{*}$ & $61.0 \pm 28.5$ & $63.5 \pm 27.3^{*}$ & $63.1 \pm 25.4$ \\
\hline General health & $37.1 \pm 20$ & $36.9 \pm 21.1$ & $34.4 \pm 21.5^{*}$ & $34.7 \pm 17.5$ & $40.7 \pm 18.1^{*}$ & $38.0 \pm 14.1$ \\
\hline Vitality & $43.1 \pm 20$ & $43.9 \pm 21$ & $42.1 \pm 23.6$ & $37.1 \pm 19.2$ & $45.2 \pm 22.4^{* *}$ & $41.9 \pm 19.7$ \\
\hline Social function & $51.0 \pm 23.8$ & $50.3 \pm 25.3$ & $45.8 \pm 26.9^{*}$ & $49.1 \pm 17.1$ & $54.1 \pm 22.5$ & $51.7 \pm 22.3$ \\
\hline Role emotional & $39.6 \pm 30.7$ & $38.7 \pm 31.3$ & $35.8 \pm 29.8$ & $39.4 \pm 25.8$ & $46.7 \pm 27.1^{*}$ & $45.9 \pm 28.8$ \\
\hline Mental health & $50.7 \pm 18.7$ & $52.6 \pm 20.5$ & $47.5 \pm 21.8$ & $49.3 \pm 18.9$ & $55.4 \pm 17.4^{* *}$ & $54.5 \pm 19.2^{*}$ \\
\hline
\end{tabular}

Values are mean \pm SD. TDI $=$ Transition dyspnea index; HF $=$ handgrip force.

${ }^{*} \mathrm{p}<0.05$; ${ }^{* *} \mathrm{p}<0.01$ compared with baseline in each group. 
Table 3. Comparison of changes in the IPF and COPD groups after pulmonary rehabilitation

\begin{tabular}{|c|c|c|c|c|c|c|}
\hline \multirow[t]{2}{*}{ Outcome measures } & \multicolumn{2}{|l|}{ After 8 weeks } & \multirow{2}{*}{$\begin{array}{l}\mathrm{p} \\
\text { value }\end{array}$} & \multicolumn{2}{|l|}{ After 6 months } & \multirow{2}{*}{$\begin{array}{l}\mathrm{p} \\
\text { value }\end{array}$} \\
\hline & $\begin{array}{l}\text { IPF group } \\
(\mathrm{n}=36)\end{array}$ & $\begin{array}{l}\text { COPD group } \\
(\mathrm{n}=40)\end{array}$ & & $\begin{array}{l}\text { IPF group } \\
(\mathrm{n}=30)\end{array}$ & $\begin{array}{l}\text { COPD group } \\
(\mathrm{n}=37)\end{array}$ & \\
\hline \multicolumn{7}{|c|}{ Dyspnea and functional status } \\
\hline MRC grade & $-0.4(-0.6$ to -0.3$)$ & $-0.8(-0.9$ to -0.6$)$ & 0.011 & $-0.1(-0.3$ to 0.2$)$ & $-0.6(-0.8$ to -0.4$)$ & 0.001 \\
\hline TDI score & $0.8(0.2$ to 1.4$)$ & $1.8(1.4$ to 2.2$)$ & 0.04 & $-0.9(-1.2$ to -0.6$)$ & $0.9(0.45$ to 1.35$)$ & 0.001 \\
\hline \multicolumn{7}{|l|}{ Muscle force } \\
\hline $\mathrm{HF}, \mathrm{kg}$ & $0.8(0.2$ to 1.5$)$ & $1.4(1.1$ to 1.6$)$ & 0.006 & $0.1(-0.8$ to 1$)$ & $0.9(0.6$ to 1.2$)$ & 0.007 \\
\hline $\mathrm{QF}, \mathrm{kg}$ & $2.0(0.9$ to 3.1$)$ & $5.4(4.4$ to 6.4$)$ & 0.001 & $0.01(-1.2$ to 1.2$)$ & 4.1 (3.0 to 5.2$)$ & 0.001 \\
\hline QF, \% body weight & $4.3(1.8$ to 6.7$)$ & $10.2(8.5$ to 11.8$)$ & 0.001 & $0.2(-2$ to 2.4$)$ & $7.7(5.8$ to 9.6$)$ & 0.001 \\
\hline \multicolumn{7}{|l|}{ Exercise capacity } \\
\hline 6MWD, m & $16.2(7.1$ to 25.4$)$ & 53.1 (44.9 to 61.2$)$ & 0.001 & $-21.7(-30$ to -13.4$)$ & $49.2(38.9$ to 59.4$)$ & 0.001 \\
\hline \multicolumn{7}{|l|}{$\mathrm{ADL}$} \\
\hline ADL score & $1.1(0.8$ to 1.3$)$ & $1.5(1.2$ to 1.7$)$ & 0.04 & $0.5(0.2$ to 0.8$)$ & $1.5(1.2$ to 1.9$)$ & 0.001 \\
\hline \multicolumn{7}{|l|}{ SF-36 Scale } \\
\hline Physical functioning & $1.9(-1.1$ to 5$)$ & $7.0(2$ to 12$)$ & 0.163 & $-2.0(-5.4$ to 1.4$)$ & $5.5(0.7$ to 10.4$)$ & 0.007 \\
\hline Role physical & $1.0(-1.6$ to 3.6$)$ & 9.9 (3.8 to 15.9$)$ & 0.002 & $-5.0(-10.3$ to 0.3$)$ & $6.4(-0.9$ to 13.7$)$ & 0.009 \\
\hline Bodily pain & $-2.7(-8.2$ to 2.7$)$ & $2.6(0.5$ to 4.6$)$ & 0.03 & $-3.9(-8.3$ to 0.4$)$ & $-0.3(-3$ to 2.4$)$ & 0.251 \\
\hline General health & $-0.2(-2.8$ to 2.4$)$ & $6.0(0.1$ to 11.8$)$ & 0.012 & $-4.2(-8.4$ to -0.1$)$ & $3.9(-1.5$ to 9.2$)$ & 0.035 \\
\hline Vitality & $0.9(-1.9$ to 3.6$)$ & 8.1 (4.3 to 11.9 ) & 0.014 & $-0.8(-4.5$ to 2.9$)$ & $3.9(-0.5$ to 8.2$)$ & 0.221 \\
\hline Social function & $-0.7(-3.2$ to 1.8$)$ & $5.0(-0.3$ to 10.3$)$ & 0.055 & $-5.0(-9.2$ to -0.8$)$ & $2.4(-4.2$ to 8.9$)$ & 0.086 \\
\hline Role emotional & $-0.9(-5.4$ to 3.6$)$ & $7.3(1.4$ to 13.1$)$ & 0.006 & $-3.9(-8.8$ to 1$)$ & $5.6(-1.5$ to 12.7$)$ & 0.014 \\
\hline Mental health & $1.9(-1.1$ to 5$)$ & $6.1(3.5$ to 8.8$)$ & 0.019 & $-1.0(-3.9$ to 1.9$)$ & $4.1(0.01$ to 8.1$)$ & 0.043 \\
\hline
\end{tabular}

Values given as mean difference (95\% CI is shown in parentheses) between baseline and 8 weeks, and baseline and 6 months after the program. A positive score indicates improvement except for MRC grade. TDI = Transition dyspnea index; HF = handgrip force.

The change in 6MWD was positively correlated with the change in QF in both groups (IPF, $\mathrm{r}=0.43, \mathrm{p}=0.013$ vs. COPD, $r=0.35, p=0.023$ ). In the IPF group, there was an inverse relationship between the mean daily dose of oral corticosteroids and change in QF $(\mathrm{r}=-0.62, \mathrm{p}=$ 0.04). Further, the improvement in QF was less in subjects taking oral corticosteroids than those not receiving corticosteroids (IPF, $-0.2 \pm 1.0$ vs. $3.3 \pm 3.5 \mathrm{~kg}, \mathrm{p}=0.002$; COPD, $2.0 \pm 2.8$ vs. $5.8 \pm 2.8 \mathrm{~kg}, \mathrm{p}=0.016$, respectively).

In both patient groups, all indices of pulmonary function had significantly declined at the 6-month follow-up when compared to baseline measures. Forced expiratory volume in $1 \mathrm{~s}$ and forced vital capacity in the COPD cohort were the only exceptions (table 4).

\section{Discussion}

The present study is the first prospective controlled trial to evaluate the effects of pulmonary rehabilitation in subjects with IPF who have functional limitation, and to compare the responses to rehabilitation to those seen in a cohort with COPD. Because the mechanisms of exercise limitation are different in the two disease cohorts, we matched subjects for age and MRC grade. At the baseline assessment, the groups were similar in terms of exercise capacity (6MWD, PWR), functional status (ADL score) and health status (SF-36 scores). Thus, we consider that a comparison of response to rehabilitation in these two distinct disease cohorts is valid. Although the rehabilitation program significantly improved dyspnea, muscle force, exercise capacity and ADL in both groups, health status did not change in the IPF group. Further, the magnitude of improvement was significantly less in the IPF group, although both groups presented with similar levels of disability at baseline assessment. Moreover, at 6 months after completion of the program, the improvements were no longer evident in the IPF group, although they were well maintained in the subjects with COPD. Thus, this study demonstrates that a pulmonary rehabilitation program based on guidelines for subjects with COPD has limited efficacy when applied to individuals with advanced IPF. 
Table 4. Pulmonary function data of the subjects who completed the program at baseline and at 6 months following pulmonary rehabilitation

\begin{tabular}{|c|c|c|c|c|c|c|}
\hline \multirow[t]{2}{*}{ Variables } & \multicolumn{3}{|c|}{ IPF group } & \multicolumn{3}{|c|}{ COPD group } \\
\hline & $\begin{array}{l}\text { baseline } \\
(\mathrm{n}=36)\end{array}$ & $\begin{array}{l}6 \text { months } \\
(\mathrm{n}=30)\end{array}$ & $\mathrm{p}$ value & $\begin{array}{l}\text { baseline } \\
(\mathrm{n}=40)\end{array}$ & $\begin{array}{l}6 \text { months } \\
(\mathrm{n}=37)\end{array}$ & $\mathrm{p}$ value \\
\hline $\mathrm{FEV}_{1}$, liters & $1.7 \pm 0.5$ & $1.6 \pm 0.5$ & 0.0001 & $1.1 \pm 0.5$ & $1.1 \pm 0.5$ & 0.265 \\
\hline FVC, liters & $2.0 \pm 0.6$ & $1.9 \pm 0.7$ & 0.0001 & $2.5 \pm 0.7$ & $2.4 \pm 0.7$ & 0.103 \\
\hline FRC, liters & $1.7 \pm 0.5$ & $1.6 \pm 0.5$ & 0.0001 & $4.2 \pm 1.0$ & $4.3 \pm 1.0$ & 0.006 \\
\hline TLC, liters & $3.0 \pm 0.8$ & $2.9 \pm 0.9$ & 0.0001 & $5.6 \pm 1.0$ & $5.7 \pm 1.1$ & 0.001 \\
\hline $\mathrm{DL}_{\mathrm{CO}}, \mathrm{ml} / \mathrm{min} / \mathrm{mm} \mathrm{Hg}$ & $6.2 \pm 2.3$ & $5.2 \pm 2.6$ & 0.0001 & $12.5 \pm 5.9$ & $12.3 \pm 5.6$ & 0.001 \\
\hline
\end{tabular}

Values are means $\pm \mathrm{SD}$. DL $\mathrm{CO}=$ Lung diffusion capacity for carbon monoxide; $\mathrm{FEV}_{1}=$ forced expiratory volume in $1 \mathrm{~s} ; \mathrm{FRC}$ = functional residual capacity; FVC = forced vital capacity; TLC = total lung capacity.

Recently, two randomized controlled trials in subjects with IPF [11] and ILD [7] provided support for the benefits of pulmonary rehabilitation. In both trials, exercise prescription was based on recommendations for individuals with COPD [12]. Nishiyama et al. [11] reported significant improvements in 6MWD and St. George's Respiratory Questionnaire in subjects with IPF who had mild impairment. Holland et al. [7] found significant improvements following rehabilitation in 6MWD, dyspnea, and the Chronic Respiratory Disease Questionnaire in a randomized controlled trial of 57 subjects with ILD (34 with IPF). However, none of the benefits were maintained at 6 months. A systematic review of exercise training in ILD also provides support for the short-term benefits of this intervention in patients with IPF [29].

Our data are consistent with the findings of Holland et al. [30], who reported only a modest improvement in $6 \mathrm{MWD}$ and a significant decline in $6 \mathrm{MWD}$ in the IPF cohort at 6-month follow-up. These authors recently reported that the threshold for a clinically significant change in 6MWD for subjects with IPF to be in the range 29-34 m [30]. Our program achieved a smaller increase in 6MWD $(16 \mathrm{~m})$ and suggests that the magnitude of improvement following pulmonary rehabilitation is modest in subjects with IPF and is not well maintained after cessation of the program.

The relatively small improvements in dyspnea and exercise capacity may have contributed to the lack of a change in health status in the IPF cohort. In COPD, exercise capacity and dyspnea are the main determinants of HRQoL [31]. Other studies in ILD and IPF cohorts have shown a relationship between improvements in dyspnea and exercise capacity $[7,11]$. Differences between the outcomes in the COPD and IPF subjects in our study may in part be due to the characteristic symptom of frequent cough and severe hypoxemia, and the use of oral corticosteroids in the IPF group.

\section{Factors Limiting Improvement following Pulmonary}

\section{Rehabilitation}

Our findings of limited short-term improvement following pulmonary rehabilitation in IPF may be explained by disease heterogeneity, the intensity of the endurance exercise achieved and the nature of the lower limb muscle weakness. Disease progression in IPF is variable [1]. Thus, the effects of pulmonary rehabilitation depend on the rate of disease progression. In our study, the majority of the IPF group had severely impaired pulmonary function and we speculate that their disease was comparatively well advanced. This may have limited the potential for subjects to gain improvements from rehabilitation.

Although we attempted to increase training intensity, severe oxygen desaturation, and paroxysms of cough and severe dyspnea limited the ability of the IPF group to increase intensity. Thus, it is likely that the intensity of exercise in this group was insufficient to achieve a physiologic training effect. Arterial hypoxemia during exercise may cause early onset of lactic acidosis in peripheral muscles and increased central drive during low-intensity exercise. Moreover, these factors contribute to the increased ventilatory demand and dyspnea.

Muscle weakness in COPD is mainly considered to be related to disuse or physical deconditioning [32], with the improvements in exercise capacity after exercise training 
occurring as a result of peripheral muscle adaptation [33]. QF was significantly lower in the IPF group at baseline and the magnitude of improvement in $\mathrm{QF}$ and exercise capacity was lower in this cohort. This finding suggests that the ability to achieve peripheral muscle adaptation following training may be limited in IPF.

Previous research demonstrated that $\mathrm{QF}$ is reduced in IPF subjects with only mild to moderate pulmonary impairment, and is related to exercise capacity [34], suggesting that the possible mechanisms responsible for this finding might include deconditioning, the inflammatory disease process of IPF and decreased levels of anabolic hormones and myopathy specific to IPF [34]. However, as yet the pathophysiology underlying QF weakness in IPF is unclear. We speculate that skeletal muscle weakness and the poor response to exercise training in subjects with IPF may be related to corticosteroid treatment. In addition, deconditioning or atrophy of skeletal muscles further contributes to the myopathy.

The lack of a sustained benefit following rehabilitation in the IPF group is consistent with a previous report [7]. Although we encouraged subjects to continue with their home-based exercise program after cessation of supervised classes, we did not provide a formal maintenance program. Several trials of pulmonary rehabilitation in COPD suggest that the benefits decline towards baseline after 6-12 months following cessation of the intervention [12]. The rapid decline in our IPF subjects could be explained by disease progression. Attrition tended to be higher in the IPF group and may also have influenced these findings. The finding that the ADL score was preserved at follow-up may be explained by the patient education component that aimed at improving the ability of subjects to undertake ADL.

\section{Limitations}

We utilized COPD subjects as a control group and did not include a control group of IPF subjects who received only usual medical care, thus limiting our ability to evaluate the longer-term effects of pulmonary rehabilitation in IPF. Because IPF is a heterogeneous disease and our sample was relatively small, we were unable to examine the effects of disease severity on responses to pulmonary rehabilitation. Although there are several instruments for evaluating disease-specific health status or HRQoL for COPD, there is no such scale for IPF. We therefore used the SF-36 the validity and reliability of which have been established in both COPD [35] and IPF [36]. However, this may have limited responsiveness. Further, we did not utilize interval training in an attempt to increase the training intensity tolerated by the IPF group. Pulmonary hypertension is frequently seen in subjects with IPF [37] and adversely affects exercise capacity [38]. We are unable to comment on the significance of pulmonary hypertension in our subjects, or the effects of exercise training on pulmonary hemodynamics because most subjects did not undergo right heart catheterization.

\section{Clinical Implications}

Exercise training prescribed using guidelines for individuals with COPD appears to be less effective in IPF subjects, hence a unique approach to training for IPF subjects is required. This should include provision of supplementary oxygen [39], specific occupational therapy interventions [40], and energy conservation strategies may be useful to control dyspnea and exercise-induced hypoxemia. Further, the optimal timing for rehabilitation in the disease trajectory requires consideration.

\section{Conclusions}

Pulmonary rehabilitation in subjects with IPF achieves only modest improvements in dyspnea, exercise capacity and ADL, but does not appear to improve health status. Further, the benefits are not maintained once training ceases. These findings contrast with the larger and longer-lasting improvements following rehabilitation seen in COPD and suggest that future research should focus on developing a pulmonary rehabilitation program specifically tailored to the needs of IPF subjects in an attempt to optimize the benefits of rehabilitation.

\section{Acknowledgements}

We thank all subjects who participated in this study. We gratefully acknowledge Drs. Naoto Rikitomi, Morihide Ando and Hiroshi Niwa for their helpful comments, and also wish to thank Dr. Sumihisa Honda for statistical advice.

References

Kozu/Senjyu/Jenkins/Mukae/Sakamoto/ Kohno
American Thoracic Society: Idiopathic pulmonary fibrosis: diagnosis and treatment. International consensus statement. American Thoracic Society (ATS), and the European Respiratory Society (ERS). Am J Respir Crit Care Med 2000;161:646-664.

-2 Swigris JJ, Kuschner WG, Jacobs SS, Wilson SR, Gould MK: Health-related quality of life in patients with idiopathic pulmonary fibrosis: a systematic review. Thorax 2005;60: 588-594. 
-3 Spruit MA, Janssen DJ, Franssen FM, Wouters EF: Rehabilitation and palliative care in lung fibrosis. Respirology 2009;14:781-787.

4 Lacasse Y, Goldstein R, Lasserson TJ, Martin S: Pulmonary rehabilitation for chronic obstructive pulmonary disease. Cochrane $\mathrm{Da}$ tabase Syst Rev 2006:CD003793.

5 Ferreira G, Feuerman M, Spiegler P: Results of an 8-week, outpatient pulmonary rehabilitation program on patients with and without chronic obstructive pulmonary disease. J Cardiopulm Rehabil 2006;26:54-60.

6 Foster S, Thomas HM 3rd: Pulmonary rehabilitation in lung disease other than chronic obstructive pulmonary disease. Am Rev Respir Dis 1990;141:601-604.

$\checkmark 7$ Holland AE, Hill CJ, Conron M, Munro P, McDonald CF: Short term improvement in exercise capacity and symptoms following exercise training in interstitial lung disease. Thorax 2008;63:549-554.

8 Jastrzebski D, Gumola A, Gawlik R, Kozielski J: Dyspnea and quality of life in patients with pulmonary fibrosis after six weeks of respiratory rehabilitation. J Physiol Pharmacol 2006;57(suppl 4):139-148.

-9 Naji NA, Connor MC, Donnelly SC, McDonnell TJ: Effectiveness of pulmonary rehabilitation in restrictive lung disease. J Cardiopulm Rehabil 2006;26:237-243.

-10 Ferreira A, Garvey C, Connors GL, Hilling L, Rigler J, Farrell S, Cayou C, Shariat C, Collard HR: Pulmonary rehabilitation in interstitial lung disease: benefits and predictors of response. Chest 2009;135:442-447.

-11 Nishiyama O, Kondoh Y, Kimura T, Kato K, Kataoka K, Ogawa T, Watanabe F, Arizono S, Nishimura K, Taniguchi H: Effects of pulmonary rehabilitation in patients with idiopathic pulmonary fibrosis. Respirology 2008;13:394-399.

-12 Nici L, Donner C, Wouters E, Zuwallack R, Ambrosino N, Bourbeau J, Carone M, Celli B, Engelen M, Fahy B, Garvey C, Goldstein R, Gosselink R, Lareau S, MacIntyre N, Maltais F, Morgan M, O'Donnell D, Prefault C, Reardon J, Rochester C, Schols A, Singh S, Troosters T: American Thoracic Society/European Respiratory Society statement on pulmonary rehabilitation. Am J Respir Crit Care Med 2006;173:1390-1413.

-13 Kurihara N, Fujimoto S, Terakawa K, Ohta K, Hirata K, Nakaoka Y, Hiraga T, Nakano Y, Nakano N, Matsushita H, et al: Exercise performance and limiting factors in patients with chronic lung diseases. Osaka City Med J 1990;36:129-139.

14 Pepin V, Saey D, Laviolette L, Maltais F: Exercise capacity in chronic obstructive pulmonary disease: mechanisms of limitation. COPD 2007;4:195-204.

15 Agusti AG, Roca J, Gea J, Wagner PD, Xaubet A, Rodriguez-Roisin R: Mechanisms of gasexchange impairment in idiopathic pulmonary fibrosis. Am Rev Respir Dis 1991;143: 219-225.
16 Harris-Eze AO, Sridhar G, Clemens RE, Zintel TA, Gallagher CG, Marciniuk DD: Role of hypoxemia and pulmonary mechanics in exercise limitation in interstitial lung disease. Am J Respir Crit Care Med 1996;154:9941001.

-17 Hansen JE, Wasserman K: Pathophysiology of activity limitation in patients with interstitial lung disease. Chest 1996;109:15661576.

18 Casaburi R, Patessio A, Ioli F, Zanaboni S, Donner CF, Wasserman K: Reductions in exercise lactic acidosis and ventilation as a result of exercise training in patients with obstructive lung disease. Am Rev Respir Dis 1991;143:9-18

19 Fletcher CM, Elmes PC, Fairbairn AS, Wood $\mathrm{CH}$ : The significance of respiratory symptoms and the diagnosis of chronic bronchitis in a working population. Br Med J 1959;2: 257-266.

20 Rabe KF, Hurd S, Anzueto A, Barnes PJ, Buist SA, Calverley P, Fukuchi Y, Jenkins C, Rodriguez-Roisin R, van Weel C, Zielinski J: Global strategy for the diagnosis, management, and prevention of chronic obstructive pulmonary disease: GOLD executive summary. Am J Respir Crit Care Med 2007;176: 532-555.

21 Miller MR, Hankinson J, Brusasco V, Burgos F, Casaburi R, Coates A, Crapo R, Enright P, van der Grinten CP, Gustafsson P, Jensen R, Johnson DC, MacIntyre N, McKay R, Navajas D, Pedersen OF, Pellegrino R, Viegi G, Wanger J: Standardisation of spirometry. Eur Respir J 2005;26:319-338.

22 Macintyre N, Crapo RO, Viegi G, Johnson DC, van der Grinten CP, Brusasco V, Burgos F, Casaburi R, Coates A, Enright P, Gustafsson P, Hankinson J, Jensen R, McKay R, Miller MR, Navajas D, Pedersen OF, Pellegrino $\mathrm{R}$, Wanger J: Standardisation of the singlebreath determination of carbon monoxide uptake in the lung. Eur Respir J 2005;26:720 735.

23 Mahler DA, Weinberg DH, Wells CK, Feinstein AR: The measurement of dyspnea. Contents, interobserver agreement, and physiologic correlates of two new clinical indexes. Chest 1984;85:751-758.

24 Kato M, Yamasaki H, Hiiragi Y, Nakajima K: Measurements of isometric knee extension force with a hand-held dynamometer: effect for interrater reliability using fixing-belt. Sogo Rihabiriteshon 2001;29:1047-1050.

25 ATS statement: Guidelines for the six-minute walk test. Am J Respir Crit Care Med 2002;166:111-117.

26 Borg GA: Psychophysical bases of perceived exertion. Med Sci Sports Exerc 1982;14:377381.

27 Spector WD, Katz S, Murphy JB, Fulton JP: The hierarchical relationship between activities of daily living and instrumental activities of daily living. J Chronic Dis 1987;40: 481-489.
28 Fukuhara S, Bito S, Green J, Hsiao A, Kurokawa K: Translation, adaptation, and validation of the SF-36 Health Survey for use in Japan. J Clin Epidemiol 1998;51:1037-1044.

29 Holland A, Hill C: Physical training for interstitial lung disease. Cochrane Database Syst Rev 2008:CD006322.

- 30 Holland AE, Hill CJ, Conron M, Munro P, McDonald CF: Small changes in six-minute walk distance are important in diffuse parenchymal lung disease. Respir Med 2009; 103:1430-1435.

- 31 Tsukino M, Nishimura K, Ikeda A, Koyama $\mathrm{H}$, Mishima M, Izumi T: Physiologic factors that determine the health-related quality of life in patients with COPD. Chest 1996;110: 896-903.

- 32 Serres I, Gautier V, Varray A, Prefaut C: Impaired skeletal muscle endurance related to physical inactivity and altered lung function in COPD patients. Chest 1998;113:900-905.

33 Sala E, Roca J, Marrades RM, Alonso J, Gonzalez De Suso JM, Moreno A, Barbera JA, Nadal J, de Jover L, Rodriguez-Roisin R, Wagner PD: Effects of endurance training on skeletal muscle bioenergetics in chronic obstructive pulmonary disease. Am J Respir Crit Care Med 1999;159:1726-1734.

- 34 Nishiyama O, Taniguchi H, Kondoh Y, Kimura T, Ogawa T, Watanabe F, Arizono S: Quadriceps weakness is related to exercise capacity in idiopathic pulmonary fibrosis. Chest 2005;127:2028-2033.

35 Mahler DA, Mackowiak JI: Evaluation of the short-form 36-item questionnaire to measure health-related quality of life in patients with COPD. Chest 1995;107:1585-1589.

-36 Martinez TY, Pereira CA, dos Santos ML, Ciconelli RM, Guimaraes SM, Martinez JA: Evaluation of the short-form 36-item questionnaire to measure health-related quality of life in patients with idiopathic pulmonary fibrosis. Chest 2000;117:1627-1632.

37 Patel NM, Lederer DJ, Borczuk AC, Kawut SM: Pulmonary hypertension in idiopathic pulmonary fibrosis. Chest 2007;132:9981006.

38 Lettieri CJ, Nathan SD, Barnett SD, Ahmad S, Shorr AF: Prevalence and outcomes of pulmonary arterial hypertension in advanced idiopathic pulmonary fibrosis. Chest 2006; 129:746-752

-39 Harris-Eze AO, Sridhar G, Clemens RE, Gallagher CG, Marciniuk DD: Oxygen improves maximal exercise performance in interstitial lung disease. Am J Respir Crit Care Med 1994;150:1616-1622.

40 Lorenzi CM, Cilione C, Rizzardi R, Furino V, Bellantone T, Lugli D, Clini E: Occupational therapy and pulmonary rehabilitation of disabled COPD patients. Respiration 2004;71: 246-251. 